\title{
Building resource capacity for IT education and training in schools - the case of Botswana
}

\author{
Sunday Ojo and Ben Awuah \\ Department of Computer Science \\ University of Botswana \\ Private Bag 0022 \\ Gaborone, Botswana \\ $\mathrm{Fax}+2673552784$ \\ E-mail: ojoso@noka.ub.bw
}

\begin{abstract}
Botswana provides an interesting case study of some issues and challenges in building the human resource capacity necessary for a programme of IT education and training in schools. Present and future education and training options for building capacity are discussed. A framework for building appropriate human resource capacity is also proposed in form of recommendations. The issues and challenges raised in Botswana's program of IT education and training in schools are not unique to Botswana, and, consequently, the proposed framework can be generalized, with appropriate adaptations, to different contexts in developing countries.
\end{abstract}

\section{Keywords}

Capacity building, curriculum development, developing countries, skills, teaching materials

Information Technology (IT) is essential to developing countries if they wish to modernize their infrastructures, survive economically, compete internationally and communicate electronically for trade and other purposes (Hawkridge, 1990). The

(C) 1998 IFIP. Published by Chapman \& Hall 
modern successful industrial economy worldwide is IT-driven. Thus each society must be IT-aware, and the present and future workforce must be prepared to make the best use of IT.

Botswana has recognized the need to increase the technological skills of its people to better compete in world markets. The Botswana education policy aims to prepare Botswana for the transition from a traditional agriculture-based economy to an IT-based industrial economy. To imbibe the IT culture early enough, most societies are introducing computer education in schools. In Botswana, the introduction of IT education and training (IT E\&T) in schools is aimed at ensuring a basic level of competence for most, and in the long run, for all young people countrywide. The intention of the programme is not to produce computer experts out of the students but to give them the basic computer knowledge and skills to make them computer literate, and enable them pursue computer studies without being intimidated by the computer. After the acquisition of the skills it is expected that the students will be able to use IT across the subjects of the curriculum (Curriculum Development Division, 1996).

The availability of human resources to the successful implementation of a programme such as this cannot be over-emphasized. Therefore, the main focus of this paper is on human resource capacity building for IT E\&T at the secondary school level of education in Botswana. The key objective is to examine the various options available for human resource capacity building strategies.

\section{IT EDUCATION AND TRAINING IN BOTSWANA'S SCHOOLS}

\subsection{Structure of Botswana's education system}

The Botswana education system can be stratified into: preprimary, primary, secondary, and post-secondary levels of education. The preprimary level is wholly a private affair and so no reliable statistics are available. There are 629 public and 71 private primary schools. The secondary level is divided into two-year (or threeyear) junior secondary and three-year senior secondary schools. At present, there are 209 junior secondary and about 27 senior secondary schools. At the post-secondary level, there are four primary teacher training colleges and two colleges of education (for training junior secondary teachers). There are also six vocational training centres and one university - to which are affiliated the two colleges of education and a college of agriculture.

\subsection{Supply of computers to schools}

According to Nganunu (1993), computers started finding their way into Botswana's secondary schools around 1982. School computers were usually donated by local businesses, Parent-Teacher Associations and nongovernmental organizations. Interested teachers and students were mainly exposed to computers through computer clubs in schools. Computers in the junior secondary schools (JSSs) were used mainly for administrative rather than educational purposes. The Ministry of Education came up with the idea of providing every senior secondary 
student with basic computer literacy in 1988 (Nganunu, 1993). The government started playing a proactive role in around 1991 and set up an inter-ministerial Government Computer Steering Committee (GCSC), with a national subcommittee on Computer Education and Training. The sub-committee was set up to advise the GCSC on pre-service and in-service education and training needs for the required human resources.

By 1992, the government had supplied five Macintosh computers each to all the senior secondary schools to enable them introduce computer awareness courses to teachers and students. One of the secondary schools which had started an ' $O$ ' level computer studies programme since 1986 was given an additional eight computers. One of the two colleges of education was also supplied with five PCs. The initiative was not based on any clearly-defined policy on computer education in schools. Recently, seven out of the 209 junior secondary schools were provided with laboratories equipped with 10 Macintoshes and 10 IBM PCs. The seven schools are currently being used for a trial run of a computer awareness programme for the junior secondary schools.

\subsection{National policy on IT E\&T in schools}

In the Botswana Government White Paper (Botswana Government, 1994) on the Report of the National Commission on Education (NCE, 1993) the need to acquire computer literacy in secondary schools for both teachers and students was recognized. The White Paper made the following policy statements:

- that computers should be provided at the proposed resource centres for primary schools;

- that each student of a junior secondary school should take a basic computer awareness course;

- that all senior secondary school teachers should acquire computer literacy and the schools should be allocated enough computers to enable all students to develop computer skills.

Those policy statements have provided the basis for the various steps taken on behalf of IT E\&T in schools in recent times.

\subsection{Syllabus development}

Senior secondary school computer awareness course development. A task force was set up by the Ministry of Education to develop the necessary computer awareness programme for senior secondary schools. The task force carried out an initial survey as a basis for its recommendations.

The task force came up with a framework for developing the programme, which involved the use of teachers from selected schools. In the end it was decided that a consultant will be employed to develop a national syllabus for IT E\&T in the senior secondary schools. To date the plan has not materialized. Senior secondary schools offering computer studies as an ' $\mathrm{O}$ ' level subject make use of the Cambridge ' $\mathrm{O}$ ' level syllabus. 
Junior secondary school computer awareness course development. In early 1996 a task force was set up by the Curriculum Division of the Department of Curriculum Development and Evaluation, Ministry of Education to come up with a computer awareness syllabus for the three-year junior secondary schools. The process of syllabus development was started with a consultancy which looked into the logistics for the development and implementation of the programme.

The three-year junior secondary school syllabus was launched in April 1997. The modules in the syllabus include: computer skills, keyboarding skills, productivity tools, word processing, spreadsheets, databases and graphics. The aim is to introduce computing to students through infusion into the subject areas. A trial run of the implementation of the syllabus is currently going on in seven selected junior secondary schools. According to the officer in charge, things are going well in some of the schools and not so well in others.

Presently there is no similar syllabus for the senior secondary schools. The plan is to have a national computer studies syllabus for senior secondary schools in the near future.

\section{Human resource development efforts}

The Teacher Training Development Unit (TTDU) of the Ministry of Education was charged with the responsibility of putting in place a programme to train the Inservice Education Officers with computer awareness skills to enable them develop a syllabus and carry out teaching sessions in the secondary schools for teachers. The activities are aimed at laying a foundation for the teachers to acquire the skills and enable them to teach computer awareness as a subject to students.

Vendors were initially engaged in training teachers on the management of the IT resources and the use of productivity software packages.

In 1994, based on the advice of the Commonwealth Secretariat in London, a consultant was employed to come up with a programme for 'Training the Trainers'. The consultants' proposal (Tekateka \& Miyanda, 1994) was based on visits to selected schools. A key finding was that besides individual efforts of interested staff, there was no comprehensive strategy to build the human resource capability for IT E\&T in schools. It was recommended that the Ministry of Education should initiate a programme of training 60 teachers in Gaborone, the capital city, starting in January 1995. It was also recommended that the programme should focus on providing a foundation for the understanding of IT as well as the effective use of computers in schools and industry. Each class of 10 students was to last for six weeks. The trainees should have acquired enough knowledge to use computers and be able to teach others basic computer awareness at the end of the course. A number of other observations were made in the report including:

- selection of teachers for training should not be limited to only mathematics and science teachers as this would give an incorrect impression on the status of computers in general;

- teaching a computer awareness course in itself is not a job that many teachers would want to do for the full working week so computer awareness teachers should still teach part-time in their own departments;

- teachers do not need a qualification to teach a computer awareness course. In this sense, the computer awareness course is a subject which is different from 
all others. Teachers who are familiar with some basic knowledge of computers turn out to be competent computer awareness teachers; expertise is not required;

- there should be three to four teachers skilled in computers per school, with one of them appointed as the computer coordinator.

The Teacher Training Department (TTD) organized a number of training workshops for teachers in selected schools. At the beginning of 1997, under the auspices of the pre-service unit, one of the colleges of education started a computer education programme aimed at training teachers for the junior secondary schools' computer awareness programme.

A programme has commenced for the training of teachers in the seven selected schools through the in-service programme. All teachers, regardless of their teaching subjects, are being involved. It is planned that the scheme will be extended to other schools based on the outcome of the pilot programme in the selected schools.

The Botswana government's full commitment to the programme of introducing computers in schools is not doubted. Also, right from the outset it was obvious that the government realized the significance of building the human resource capacity necessary for a successful implementation of the programme but we believe that there is a need to adopt a more comprehensive strategic approach to building IT capacity.

\section{HUMAN RESOURCE CAPACITY BUILDING - AVAILABLE OPTIONS}

The options for human resource capacity building can be categorized into in-service and pre-service. The in-service option is aimed at enhancing the capacity of serving teachers to be able to teach and effectively utilize IT in their schools. The preservice option deals with IT E\&T for trainee teachers to build in them the capacity to teach and utilize IT in the schools where they may be teaching after leaving college.

\subsection{Options for the in-service programme}

\section{Short courses in private computer training schools}

The short courses are essentially prepackaged training programmes for PC-based applications. The teachers had difficulty transferring their PC-based training to using the Macintosh systems in their schools. This suggests some fundamental deficiency in the nature of the training. The decision to supply both Macintoshes and PCs to schools from now on may not be unconnected with this experience.

\section{Vendor training programmes}

Vendor-delivered programmes are designed and implemented by IT system vendors/suppliers, and are limited to equipping trainees with the knowledge and skills required to use the specific hardware and software systems being sold by the vendors. Such training is commonly narrow and skill-oriented, and does not 
adequately prepare the trainees for the broad challenge of IT deployment in the education sector in general.

\section{Training workshops}

The Teacher Training Department organizes workshops which are conducted by officials of the Ministry of Education or the INSET (in-service training) staff based at the University of Botswana's Department of Mathematics and Science Education. The workshops are more or less devoted to computer appreciation topics and are developed in-house with the assistance of consultants. It is questionable whether the workshops take an holistic view of the total knowledge and skill requirements for teaching, using and managing IT in schools..

\section{Options for the pre-service programme}

Options for training are also available at the teacher training colleges and at the university. The college of education option for the introduction of computer education into the curriculum of the colleges of education for training teachers for the junior secondary schools was started in early 1997 (Molepolole College of Education, 1997). It is a cross-curricular approach where all IT delivery is by subject teachers and students receive no specific IT teaching per se. The challenge is that IT education and training for the student teachers requires more than just impacting the basic knowledge of computing. It requires delivery of the appropriate methodology to use the knowledge within the context of other teaching subjects. Merging the subject matter contents with pedagogical approaches in a complementary manner is important Naturally, the course would require the availability of experienced teachers. Also, the focusing of the course mainly on computers in education seems a good strategy to ensure graduates are not lost to more lucrative jobs outside the education sector $-e . g$. to industry as is experienced in other countries (Ojo, 1994).

\section{Options within the University of Botswana}

As a matter of policy, the country's National Development Plan 7 expects all students passing through the university to be computer aware before they can graduate. Consequently, virtually all programmes have computer awareness modules or IT-related courses infused into the subjects.

Recently, the Department of Mathematics and Science Education (DMSE) came up with a proposal aimed at producing teachers for Computer Education during the National Development Plan 8 (NDP8) (DMSE, 1996). The proposal was made to start a B. Ed degree as well as postgraduate Diploma in Education (PGDE) programmes in computer science. The programmes are intended to provide teachers of computer studies for the senior secondary schools. The Ministry of Education and related agencies have relied on expatriates or deployed mathematics and science teachers with basic knowledge of computing to teach the subject. This has been the practice despite the shortfall of mathematics and science teachers at the senior secondary school level. Another important observation made in the proposal is that mathematics and science teachers who graduated from the university will not have studied enough computing courses during their training. Closely related to the limited exposure to computer studies of the teachers is the question of pedagogical 
issues of teaching a subject which they will not have covered in the teacher education programmes. The cadre of mathematics and science teachers might not be sufficiently well-prepared to handle computer studies because of its uniqueness. Therefore the major focus of the programme is to produce computer studies teachers for the nation's senior secondary schools. In addition, it is hoped that the graduates of the programmes will serve in junior secondary schools to coordinate the basic computer awareness course and offer technical and academic advice. It is thought that providing teachers in this way would ensure the sustainability of the computer awareness course at the junior secondary school level.

The Department of Mathematics and Science Education has recently requested the inclusion of computer science courses in the B. Ed. (Science) programme. In this way the B. Ed. (Computer Science) programme would be comprised of a combination of courses which are selected independently by the two departments from education and computer science courses.

One problem with the combined major programme is that there are usually no clearly-defined objectives for the kind of human resource development that the programme is aimed at producing. Disciplines such as biochemistry emerged from the combination of chemistry and biology with emergent properties of its own. The combination of education and computer science should ensure producing the right kind of teachers for IT E\&T programmes in schools.

KEY ISSUES IN BUILDING THE HUMAN RESOURCE CAPACITY

\subsection{Teacher trainers}

At present there is an acute shortage of human resources to train the needed teachers. People with combination of IT knowledge and skills plus the relevant pedagogical skills are rare.

\subsection{Rural-urban infrastructural disparity}

Botswana is one of the developing countries which can boast of adequate electricity and telecommunications infrastructures - the availability of which is sine qua non for successful IT. However, as it is the case with most developing countries, the rural infrastructures are not comparable to those of the urban areas. How do we ensure that the schools in the rural areas are not unnecessarily disadvantaged? Do we need special training so teachers deployed to the rural schools know how to maintain and effectively utilize IT resources in the face of inadequate infrastructure?

\subsection{Teaching materials}

As mentioned in the preceding section, no teaching materials have been developed as of now and so the schools already involved in the programme mainly depend on operating system manuals. The implication of this is that teaching may have a purely technical focus, which is rather narrow. The development of appropriate teaching materials is a crucial operational issue. 


\subsection{Expatriate dependency}

As with other developing countries, Botswana is still at a developmental stage. There is a high dependency on expatriates, especially in the areas of science and technology. A recent study (Christopher, 1993) showed that $80 \%$ of trainers in private IT training institutions in the country are expatriates. The situation is worse in the only university, where the percentage is even higher for expatriates involved in IT E\&T. On the one hand, there is the urgency to meet the immediate developmental needs of the populace and the irresistible temptation to keep making use of imported expertise to achieve these targets/objectives. On the other hand is the need to develop the internal human resource capacity crucial to ensuring the sustainability of development. How would these apparently conflicting objectives be resolved to guarantee the sustainability of any programme of human resource capacity building for IT E\&T in schools? This is another crucial issue.

\subsection{Balancing investments in IT E\&T with other pressing demands}

IT E\&T in schools is just one of several areas for which the country needs to develop human resources capacity. Balancing resource allocation among the competing areas of need is a critical issue. Making the issue even more critical is the fact that education is virtually free in the country and investments in education do not yield immediate observable dividends.

\subsection{Indigenous capacity building}

Getting students interested in science and technology disciplines remains a major problem. There is a limit to what can be achieved in building the required indigenous capacity without adequate local supply of potential trainees. Though the government has started encouraging interests through the awarding of scholarships, there is still a long way to go to attain adequate supply of locals in this area. Also, there has to be a more conscious effort to promote and encourage the development of local talents, a crucial factor in guaranteeing indigenous capacity development.

\subsection{Curricular innovation}

Faced with the need to adapt science teaching to the local needs of their respective countries, science educators have, for some years past, embarked on curricula innovation projects. IT E\&T programme innovation requires an adaptation to local needs. Local needs analysis is a commonly neglected aspect of IT E\&T programme development in Africa. This means that trainers who are experienced in this kind of task may be lacking. The implication is that there have to be appropriate mechanisms to monitor such changes as well as adequate flexibility built into IT E\&T programmes in order to accommodate the changes. Generally, the task requires an innovative and adaptive approach, all of which makes IT E\&T programme innovation a critical issue with an enormous pedagogical challenge. 


\subsection{Maintaining the human resources capacity}

With particular reference to the B. Ed. (Computer Science) programme, we must ask how we ensure maintaining competitiveness of the programme against more attractive job markets. As a matter of strategy, we should aim at evolving a programme which provides competencies to:

- teach the secondary school computer studies syllabus;

- analyse, design, implement, evaluate and manage appropriate computers-ineducation programmes;

- determine computing resource requirements and manage computer laboratory facilities in schools;

- utilize computers in education administration.

\section{RECOMMENDATIONS}

Botswana stands a good chance of evolving IT E\&T programmes that appropriately address the various problems found in other African countries. Now we need to build more solidly on the various positive steps that have been taken so far through a more deliberate approach of developing trainers for IT E\&T programmes in schools.

\subsection{General capacity building}

To achieve general capacity building we recommend the following a series of initiatives:

- Introduce general science and technology awareness programmes in both primary and secondary school levels aimed at creating a general science and technology culture in the students.

- Carry out a national needs analysis to provide a focus for all IT E\&T programmes in schools. The analysis should be well-aligned with overall national socioeconomic goals.

- Develop a national curricula standard, innovatively designed and based on the result of the needs analysis.

- Provide a clear and definite scheme for evaluating/accrediting IT E\&T programmes.

- Formulate IT E\&T policies and strategic plans well-aligned to the overall national plan for human resources capacity development.

- Make a periodic review and update of all of the above to ensure that technological and contextual dynamics of IT are adequately catered for at every point in time.

\subsection{Institutional resource capacity building}

The human resource capacity required for IT E\&T programmes in schools should be acquired through the existing teacher training infrastructures in colleges of 
education and the teacher training departments of the university with the following recommended actions:

- Computer studies should be introduced as a teaching subject for both the Bachelors and sub-degree teacher training programmes.

- In view of the scarcity of mathematics and science teachers, other categories of students, including social science and humanities education students, should be involved as trainee teachers in the programme to involve more teachers in IT instruction.

- To ensure availability of the graduates for the purpose for which they have been trained, there should be a clearly-stated government policy as well as appropriate incentive mechanisms aimed at avoiding losing students to greener pastures in other sectors.

\subsection{Curriculum development}

The subject matter content of the curricula for training trainers should take a sociotechnical perspective so that trainers can sensitize their trainees in schools to some of the contextual issues of IT in the country. Therefore it is recommended that:

- The development of the programmes should receive input from a broad spectrum of the various role players - educationists for methodological content, IT specialists for subject matter and material content, representatives of employers and government for sociophilosophical and policy content as well as specialists in relevant subject areas for contextual issues.

- The curricula for teachers should include building capacity for graduates who are adequately equipped to effectively function in various positions of responsibility for IT E\&T in schools. Skills should include defining and planning schools' IT systems as well as designing, implementing and managing the development and operations of those systems. This requires adoption of a flexible paradigmatic framework and diversified curricula orientation to accommodate the diverse backgrounds of the prospective students to be trained for the IT E\&T programme.

In any programme of training the required teachers must establish cooperation among relevant academic departments. The nature of such cooperation is crossdisciplinary and should involve the computer science department and relevant departments in engineering, social sciences, humanities and education. The cooperation should cover areas of teaching, research, seminar and curriculum development. The educationists are needed for handling the various pedagogical issues involved in teaching and curriculum development while others will be required for the contextual issues. This kind of cooperation is needed for evolving the socioscientific-humanistic paradigmatic integration that is required for the new point of view in IT E\&T programmes. It would also enable the sharing of human and material resources for teaching and research such that the inadequacies of one department are covered by the strengths of another. 
Periodic remedial training programmes for trainers in IT E\&T programmes should occur to update their knowledge and give them the right orientation for producing appropriate human resources.

Appropriate programme evaluation and review bodies should be established to ensure continual relevance of the human resources being developed.

The establishment of an appropriate forum where IT trainers, researchers and other stakeholders can meet to share ideas, facilities, and engage in joint research and development project activities should be facilitated. Such a forum can be in the form of a well-equipped national IT Research, Development, Education and Training Centre. Such a centre should also serve as a base to generate ideas on the direction which IT E\&T programmes should be going at each point in time.

The Botswana IT E\&T programme should aim for innovations that can produce the right calibre of IT human resources. The programme should be carefully designed so that it is appropriately adapted to the sociocultural and organizational contexts of the country. This requires inward-looking rather than the usual dependence on imported expertise. It is hoped that the recommendations made for Botswana would prove helpful, not only to Botswana, but also to other developing countries sharing similar context of socioeconomic development.

\section{REFERENCES}

Botswana Government White Paper on the Revised National Policy on Education, No 2 (1994) Gaborone, Botswana.

Christopher, A. (1993) Report of a Survey on Existing and Planned Computer Training in Botswana. Gaborone, Botswana.

Curriculum Development Division of the Ministry of Education. (1996) ThreeYear Junior Secondary Syllabus - Computer Awareness. Ministry of Education, Gaborone, Botswana.

Department of Mathematics \& Science Education (1996) University of Botswana, NDP 8 Proposal, Ministry of Education, Gaborone, Botswana.

Hawkridge, D. (1990) Creative gales and computers in third world schools in Computers and Education (eds. O. Boyd-Barrett and E. Scanlon),

National Commission on Education Report (1993), Gaborone, Botswana.

Nganunu, M. (1993) Ministry of Education Policy on Computer Training, Department of Technical Education, Ministry of Education, Gaborone, Botswana.

Ojo, S.O. (1994) IT Education and Training in Africa - A Framework for Botswana. A paper presented at the Commonwealth Association of Science, Technology and Mathematics Educators (CASTME) International Conference, Gaborone, Botswana.

Tekateka, W. and Miyanda, S. (1993) Proposal to the Botswana Government for the 'Training the Trainers' Computer Programme, Access Information Systems Training Dept., Zambia. 
S.O. Ojo holds a Ph.D. in Computer Science from the University of Glasgow. He is the University of Botswana's representative to the National Sub-committee on Computer Education and Training. Dr.Ojo was the President of the Botswana Information Technology Society (BITS) from 1993 to 1996.

E.B. Awuah holds a Ph.D. in Computer Science from the University of Reading, UK and is the Head of the Department of Computer Science, University of Botswana. 